\title{
An Algorithm to Distinguish Ischaemic and Non-ischaemic ST Changes in the Holter ECG
}

\author{
P Langley, EJ Bowers, J Wild, MJ Drinnan, J Allen, AJ Sims, N Brown, A Murray \\ Freeman Hospital \& Newcastle University, Newcastle upon Tyne, UK
}

\begin{abstract}
Changes in the ECG ST segment are often observed in patients with myocardial ischaemia. However, nonischaemic changes in ST level are also common thereby limiting ischaemia detection accuracy. The aim of this study was to devise an algorithm and determine its accuracy in distinguishing between ischaemic and nonischaemic changes in the ECG ST-segment, using expertly annotated ECG data sets as a gold standard reference. The algorithm considered only the change in $S T$ relative to a baseline $S T$ level ( $\triangle S T$ ) provided by the PhysioNet database, and based on simple level thresholding within specified time windows. An initial score of $82.3 \%$ (accuracy $91.1 \%$, with sensitivity $99.0 \%$ and specificity $88.8 \%$ ) was achieved for the learning set. By making slight modifications to the algorithm and introducing principal components of ST it was not possible to improve the original algorithm. The original algorithm was therefore left as our challenge entry achieving an accuracy of $90.7 \%$ for the test data set (score of $81.4 \%$, entry 1, 1 May 2003).
\end{abstract}

\section{Introduction}

Therapeutic intervention to reduce transient myocardial ischaemic episodes could significantly improve the quality of life in affected subjects by reducing morbidity and mortality. The current methods of diagnosing these ischaemic events include cardiovascular imaging of the coronary arteries [1]. However, such specialised and resource intensive techniques are, arguably, unsuitable for studying ischaemic events brought on by activities of daily living in any one individual. Another technique, based on the analysis of the ECG waveform, has shown promise since abnormalities in the repolarization of ischaemic myocardial regions are visible in the ST segment of the ECG $[2,3]$. Although changes in ST elevation/depression can be quantified they can also occur because of a wide variety of other causes, including changes in heart rate, conduction pattern, hyperventilation, electrolyte abnormalities, response to medication, response to temperature changes, position of the subject, and noise in the ECG [4,5]. Despite these uncertainties, ECG measurements can be highly sensitive, easy to do, and lend themselves to ambulatory (e.g. 24 hour) assessments [6-8] and computer-based automated analyses [9-11]. If it were possible to accurately distinguish between ischaemic and non-ischaemic ST changes in ambulatory ECG recordings made during subjects' normal activities, the benefits could be immediate and substantial to the patient.

The aims of this study were therefore a) to produce a novel algorithm to distinguish ischaemic and nonischaemic ST changes in the ECG waveform and b) to determine the accuracy of the algorithm using expertly annotated ambulatory ECG data sets as a reference.

\section{Methods}

\subsection{Basic algorithm}

Data for the changes in ST $(\Delta \mathrm{ST})$ provided by PhysioNet were used. An example of $\Delta \mathrm{ST}$ is shown in figure 1. Event start times $\left(T_{\mathrm{s}}\right)$, for which the expertly classified ST changes (ischaemic or non-ischaemic) were known, were also provided and used in the development of the algorithm. $\Delta \mathrm{ST}$ represents the difference in ST between the current ST level and the baseline level. Principal components of ST provided by PhysioNet were also used in the optimization of the algorithm.

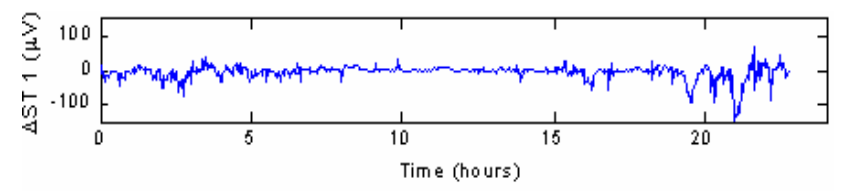

Figure 1. Example 24 hour $\Delta \mathrm{ST}$ recording from learning data set, as provided by PhysioNet.

The algorithm was based on the premise that ischaemic ST changes are large relative to non-ischaemic changes and that they are maintained for a period of time. The algorithm classified events as ischaemic if at the start of the event $\Delta \mathrm{ST}$ was greater than a threshold $\Delta \mathrm{ST}$ $\left(\mathrm{V}_{\text {thres}}\right)$, and before the end of the event $\Delta \mathrm{ST}$ maintained a minimum level $\left(\mathrm{V}_{\min }\right)$ for a period of time $\left(\mathrm{T}_{\min }\right)$. 


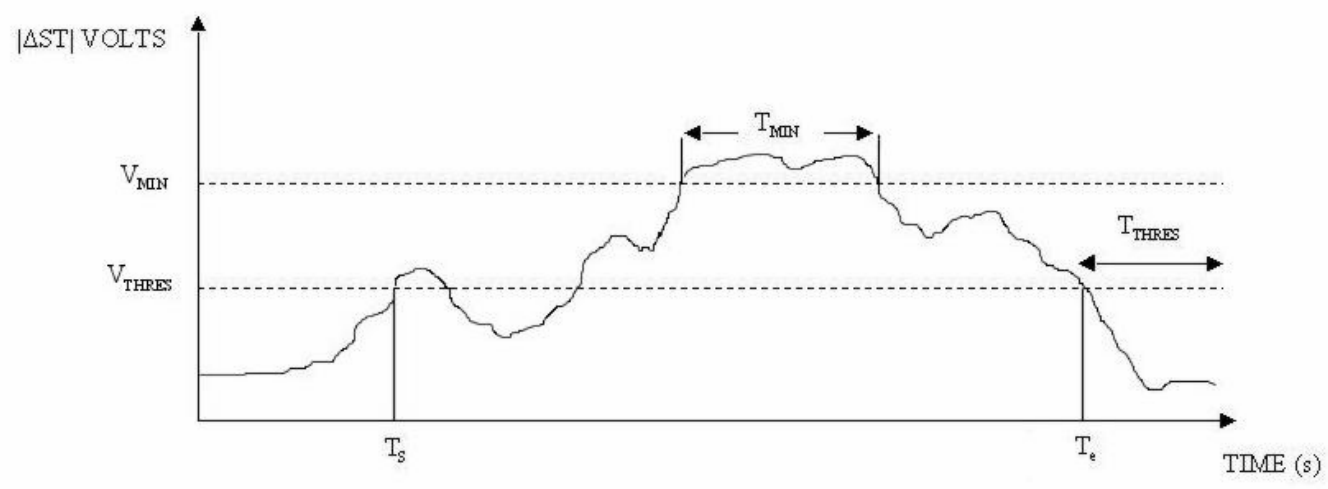

Figure 2. Illustration of amplitude thresholds and time intervals used in the algorithm.

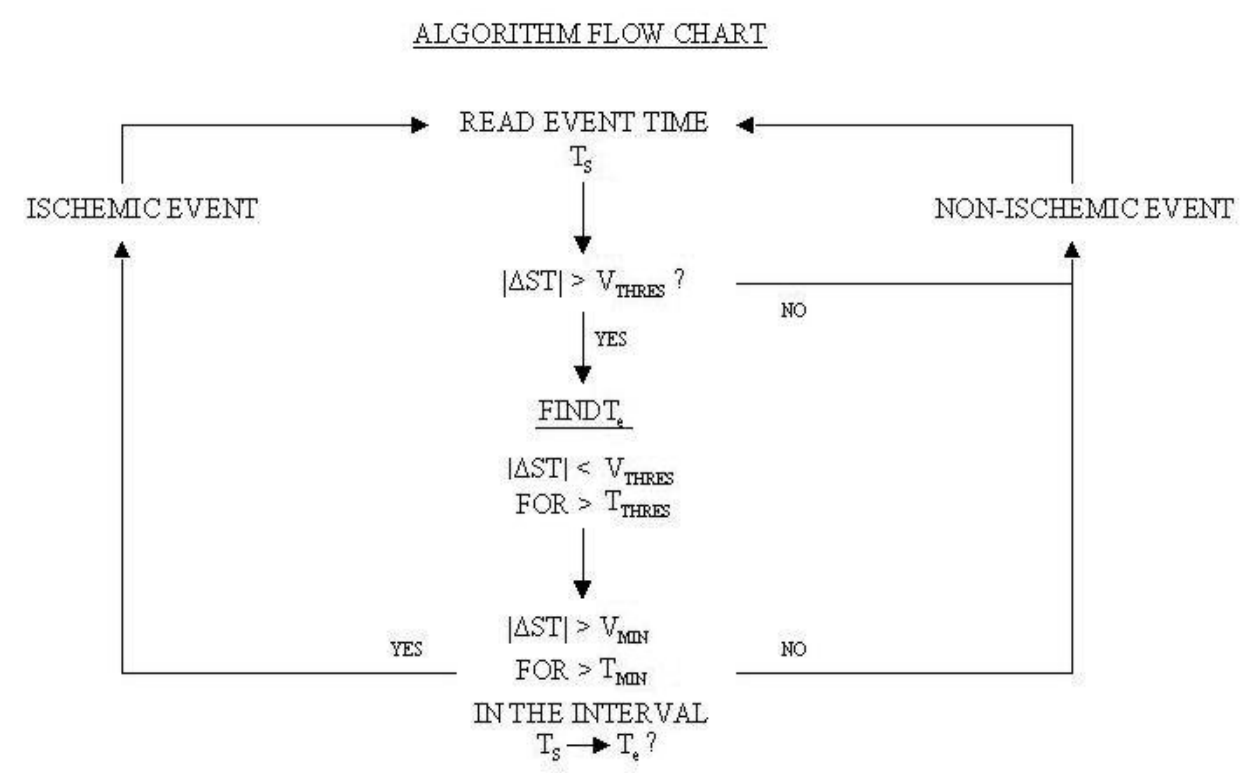

Figure 3. Flow chart for automatic ischaemic event classification.

The end of an event $\left(\mathrm{T}_{\mathrm{e}}\right)$ was defined as the time at which $\Delta$ ST fell below the threshold for a further period of time $\left(\mathrm{T}_{\text {thres }}\right)$. Figure 2 defines the relevant $\Delta \mathrm{ST}$ and time thresholds. Figure 3 provides a flow chart for the automatic classification of events.

This basic algorithm gave results that were highly sensitive (identified nearly all ischaemic events) but not specific (many non-ischaemic events were classified as ischaemic), see section 3.1.

\subsection{Algorithm optimization}

With a view to optimizing the algorithm, we investigated the effect of reclassifying as non-ischaemic those events which were classified as ischaemic by the algorithm according to; i) the number of threshold crossings and ii) thresholds on the Mahalanobis distance from the first five principal components of the ST signals. 


\subsubsection{Number of threshold crossings}

We hypothesized that in ischaemia ST changes would occur rapidly with fewer crossings of the threshold voltage than artifactual ST changes. An additional parameter, the number of threshold level crossings $\left(\mathrm{N}_{\text {cross }}\right)$ for a specified threshold level $\left(\mathrm{V}_{\text {cross }}\right)$, was calculated for those events classified as ischaemic.

\subsubsection{Principal component analysis}

Principal component analysis of the ST time series has been reported to be more sensitive to ischaemic changes. Threshold levels were applied to the time series of the Mahalanobis distance from the first five principal components of the ST. For events classified as ischaemic by the basic algorithm, these events were reclassified as non-ischaemic if in the principal component time series the threshold level $\left(\mathrm{V}_{\mathrm{kltmin}}\right)$ was not maintained for a period $\left(\mathrm{T}_{\mathrm{kltmin}}\right)$.

\subsection{Analysis}

To evaluate the algorithms under different $\Delta \mathrm{ST}$ and time thresholds, the sensitivity, specificity, accuracy and challenge score (number of correct classifications number of incorrect classifications (\%)), were calculated.

\section{Results}

\subsection{Basic algorithm}

The results for altering the values of $\mathrm{V}_{\min }, \mathrm{T}_{\min }$ and $\mathrm{T}_{\text {thres }}$ while keeping Vthres $=50 \mu \mathrm{V}$ are shown in table 1 . Figure 4 shows examples of $\Delta \mathrm{ST}$ for which correct and incorrect classifications were made.

Table 1: Results from the learning set to investigate the effect of altering three variables.

\begin{tabular}{ccccccc}
\hline $\begin{array}{l}\mathrm{V}_{\min } \\
(\mu \mathrm{T})\end{array}$ & $\begin{array}{c}\mathrm{T}_{\min } \\
(\mathrm{s})\end{array}$ & $\begin{array}{c}\mathrm{T}_{\text {thres }} \\
(\mathrm{s})\end{array}$ & $\begin{array}{c}\text { Sensitivity } \\
(\%)\end{array}$ & $\begin{array}{c}\text { Specificity } \\
(\%)\end{array}$ & $\begin{array}{c}\text { Accuracy } \\
(\%)\end{array}$ & $\begin{array}{c}\text { Score } \\
(\%)\end{array}$ \\
\hline 100 & 30 & 40 & 99.0 & 88.8 & 91.1 & 82.3 \\
110 & 30 & 40 & 85.6 & 91.0 & 89.8 & 79.6 \\
100 & 34 & 40 & 94.3 & 89.8 & 90.8 & 81.6 \\
100 & 30 & 36 & 99.0 & 88.8 & 91.1 & 82.3 \\
\hline
\end{tabular}
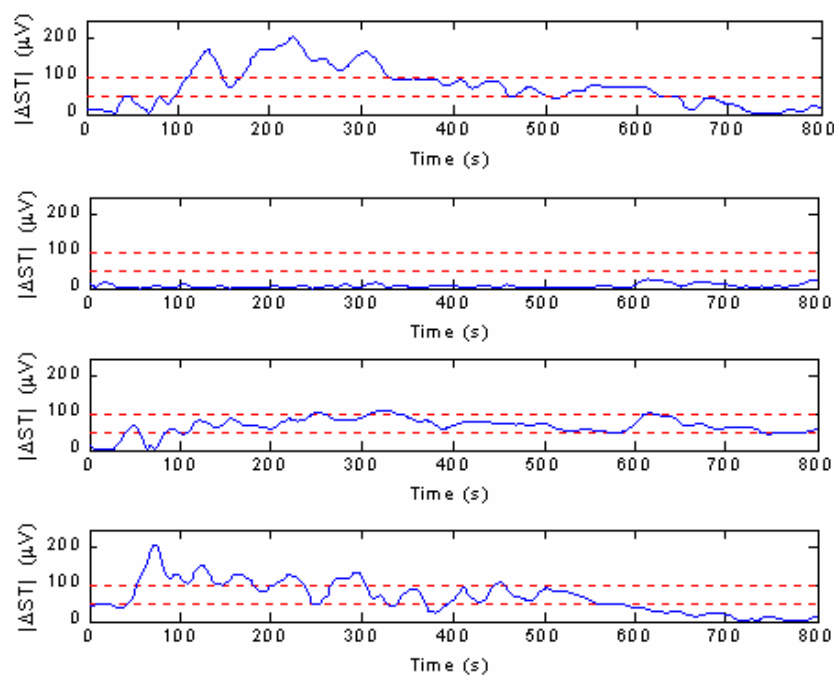

Figure 4. Examples from top to bottom of a) ischaemic event (correctly classified), b) non-ischaemic event (correctly classified), c) ischaemic event classified as non-ischaemic, d) non-ischaemic event classified as ischaemic.

\subsection{Number of threshold crossings}

We maintained $\mathrm{V}_{\text {thres }}, \mathrm{V}_{\text {min }}, \mathrm{T}_{\text {thres }}$ and $\mathrm{T}_{\min }$ at $50 \mu \mathrm{V}$, $100 \mu \mathrm{V}, 40 \mathrm{~s}$ and $30 \mathrm{~s}$ respectively and investigated the effect of altering the threshold for $\mathrm{N}_{\text {cross }}$ when $\mathrm{V}_{\text {cross }}$ equaled $50 \mu \mathrm{V}$ and $100 \mu \mathrm{V}$ as shown in table 2 below.

Table 2: Results from the learning set to investigate the effect of altering $\mathrm{N}_{\text {cross }}$ at two different thresholds.

\begin{tabular}{cccccc}
\hline $\mathrm{N}_{\text {cross }}$ & $\begin{array}{c}\mathrm{V}_{\text {cross }} \\
(\mu \mathrm{V})\end{array}$ & $\begin{array}{c}\text { Sensitivity } \\
(\%)\end{array}$ & $\begin{array}{c}\text { Specificity } \\
(\%)\end{array}$ & $\begin{array}{c}\text { Accuracy } \\
(\%)\end{array}$ & $\begin{array}{c}\text { Score } \\
(\%)\end{array}$ \\
\hline 2 & 50 & 62.0 & 95.3 & 87.8 & 75.5 \\
3 & 50 & 77.1 & 93.4 & 89.7 & 79.5 \\
4 & 50 & 84.1 & 92.0 & 90.2 & 80.3 \\
5 & 50 & 87.8 & 91.0 & 90.3 & 80.6 \\
6 & 50 & 91.6 & 90.4 & 90.6 & 81.3 \\
10 & 50 & 97.0 & 89.2 & 91.0 & 82.1 \\
25 & 50 & 99.0 & 88.9 & 91.1 & 82.4 \\
32 & 50 & 99.0 & 88.9 & 91.1 & 82.4 \\
50 & 50 & 99.0 & 88.9 & 91.1 & 82.3 \\
15 & 100 & 93.3 & 89.3 & 90.2 & 80.4 \\
25 & 100 & 95.8 & 89.1 & 90.6 & 81.3 \\
35 & 100 & 97.8 & 89.0 & 91.0 & 81.9 \\
\hline
\end{tabular}




\subsection{Principal component analysis}

Results for altering $\mathrm{V}_{\mathrm{kltmin}}$ and $\mathrm{T}_{\text {kltmin }}$ with $\mathrm{V}_{\text {thres}}, \mathrm{V}_{\text {min }}$, $\mathrm{T}_{\text {thres }}$ and $\mathrm{T}_{\text {min }}$ maintained at $50 \mu \mathrm{V}, 100 \mu \mathrm{V}, 40 \mathrm{~s}$ and $30 \mathrm{~s}$ respectively are shown in table 3 below.

Table 3: Results from the learning set to investigate the effect of altering $\mathrm{V}_{\mathrm{kltmin}}$ and $\mathrm{T}_{\mathrm{kltmin}}$

$\mathrm{V}_{\text {kltmin }} \mathrm{T}_{\text {kltmin }}$ Sensitivity Specificity Accuracy Score

\begin{tabular}{cccccc}
$(\mu \mathrm{V})$ & $(\mathrm{s})$ & $(\%)$ & $(\%)$ & $(\%)$ & $(\%)$ \\
\hline 150 & 30 & 82.9 & 90.0 & 88.4 & 76.9 \\
\hline 200 & 30 & 65.2 & 92.7 & 86.5 & 72.9 \\
\hline 160 & 20 & 82.3 & 90.2 & 88.4 & 76.9 \\
\hline
\end{tabular}

\subsection{Results with test data}

Since none of the developments we performed increased sensitivity and specificity we submitted the basic algorithm with values for $\mathrm{V}_{\text {thres }}, \mathrm{V}_{\min }, \mathrm{T}_{\text {thres }}$ and $\mathrm{T}_{\min }$ at $50 \mu \mathrm{V}, 100 \mu \mathrm{V}, 40 \mathrm{~s}$ and $30 \mathrm{~s}$ respectively. We received a score of $81.4 \%$ and gained an accuracy of $90.7 \%$.

\section{Discussion}

An algorithm designed to accurately distinguish ischaemic and non-ischaemic ST changes has been developed and tested against expertly annotated reference data. Our algorithm achieved an accuracy of close to $91 \%$ for both the learning and test data sets (test data score $81.4 \%$ ).

The basic algorithm was found to be sensitive but not specific leading us to investigate the effect of algorithm amplitude and time thresholds on accuracy and specificity for the learning data set. Here, a slight improvement in specificity ( $91 \%$ maximum) was obtained but at the cost of a marked reduction in sensitivity. A further enhancement to the algorithm then considered the number of threshold crossings and found that sensitivity and specificity values were a trade-off but the accuracy (and score) could not be improved significantly. Furthermore, the addition of the principal components from the ST measurements even slightly reduced the performance overall.

Our algorithm is simple to implement, intuitive, and straightforward to reproduce. The results demonstrate that the algorithm, based on the premise that ischaemic ST changes are large relative to non-ischaemic changes and that they are maintained for a period of time, is representative. We have shown the algorithm can reliably identify ischaemic ST changes in the ECG waveform.

\section{Acknowledgements}

Philip Langley is supported by the Engineering and Physical Sciences Research Council.

\section{References}

[1] Amanullah AM, Lindvall K. Prevalence and significance of transient predominantly asymptomatic myocardial ischemia on Holter monitoring in unstable angina pectoris, and correlation with exercise test and thallium 201 myocardial perfusion imaging. Amer J Cardiol. 1993;15:144-148.

[2] Deanfield JE, Shea MJ, Selwyn AP. Clinical evaluation of transient myocardial ischemia during daily life. Amer J Med. 1985;79:18-24.

[3] Hampton JR. The ECG in practice. 1986 Churchill Livingstone: Edinburgh.

[4] Drew BJ, Adams MG. Clinical consequences of STsegment changes caused by body position mimicking transient myocardial ischemia: hazards of ST segment monitoring? J Electrocardiol. 2001;34:261-264.

[5] Völler H, Andresen D, Brggemann T, Jereczek M, Becker B, Schröder R. Transient ST segment depression during Holter monitoring: how to avoid false positive findings. Am Heart J. 1992;124:622-629.

[6] Mickley H, Nielsen JR, Berning J, Junker A, Møller M. Serial Holter ST-segment monitoring after first acute myocardial infarction. Prevalence, variability, and longterm prognostic importance of transient myocardial ischemia. Cardiology 1998;90:160-167.

[7] Mickley H. Ambulatory ST segment monitoring after myocardial infarction. Br. Heart J. 1994;71:113-114.

[8] Jager F, Moody GB, Mark RG. Detection of transient ST segment episodes during ambulatory ECG monitoring. Comp. Biomed. Res. 1998;31:305-322.

[9] Drew JB, Pelter MM, Adams MG. Frequency characteristics, and clinical significance of transient ST segment elevation in patients with acute coronary syndromes. European Heart J. 2002;23: 941-947.

[10] Papaloukas C, Fotiadis DI, Likas A, Michalis LK. An ischemia detection method based on artificial neural networks. Artifical Intelligence Med. 2002; 24:167-178.

[11] Jager F, Taddei A, Moody GB, Emdin M, Antolic G, Dorn R, Smrdel A, Marchesi C, Mark RG. Long-term ST database: a reference for the development and evaluation of automated ischaemia detectors and for the study of the dynamics of myocardial ischaemia. Med. Biol. Eng. Comput. 2003;41:172-182.

Address for correspondence:

Philip Langley

Medical Physics Department

Freeman Hospital

Newcastle upon Tyne

NE7 7DN

UK.

philip.langley@ncl.ac.uk 